International Journal of Oceanography and Hydrobiology Volume 50, No. 2, June 2021

\title{
Incidence of skeletal deformities in induced triploid rainbow trout Oncorhynchus mykiss (Walbaum, 1792)
}

by

\author{
Krzysztof Jagiełło*, Marcin Polonis, \\ Konrad Ocalewicz
}

\section{DOI: 10.2478/oandhs-2021-0014 \\ Category: Original research paper \\ Received: June 08, 2020 \\ Accepted: October 27, 2020}

University of Gdańsk, Faculty of Oceanography and Geography, Institute of Oceanography, Division of Marine Biology and Ecology, Al. M. Piłsudskiego 46, 81-378 Gdynia, Poland

\begin{abstract}
Due to the cytogenetic incompatibility, triploid fish are usually infertile and are not affected by a decline in growth, survival and meat quality, which accompanies the process of sexual maturation in diploid specimens. Thus, artificial triploidization has been proposed for fish production in the case of species with early sexual maturation, such as rainbow trout. However, the use of this technique is limited by increased ratios of skeletal deformities observed in triploid specimens. The main objective of this research was to compare the proportion and variety of body abnormalities in diploid and triploid 14-monthold rainbow trout from commercial stocks, using external body shape examination, radiography and whole-mount skeletal staining. Individuals with externally observed body deformities (scoliosis, humpback, shortened tail and jaw deformities) accounted for $0.45 \%$ of the diploid stock and $3.83 \%$ of the triploid stock. X-rays and whole-mount skeletal staining of deformed individuals showed spine deformities, including compressions and fusions of vertebrae. Abnormalities observed in diploid and triploid rainbow trout examined during this study were non-lethal, however, they may negatively affect the condition of fish. Fish with skeletal deformities are not aesthetically pleasing, thus an increased ratio of such deformations in fish produced for commercial purposes may result in real economic losses.
\end{abstract}

Key words: fish biotechnology, induced triploids, skeletal abnormalities, aquaculture

* Corresponding author: krzjagiello@gmail.com 


\section{Introduction}

Rainbow trout (Oncorhynchus mykiss Walbaum, 1792) is one of the most important salmonid fish species in global aquaculture, with an annual production of about $800000 \mathrm{t}$ (FAO 2016). All-female stocks of rainbow trout are preferred in aquaculture because, compared to males, females gain weight faster and mature later. Sexual maturation observed in rainbow trout within the second year of rearing significantly reduces the growth rate and causes a deterioration of fillet quality. The production of sterile specimens is therefore highly required in the case of this species and triploid individuals are increasingly frequently produced under aquaculture conditions (Poontawee et al. 2007; Piferrer et al. 2009; Aussanasuwannakul et al. 2011; Lefevre al. 2015).

The term 'triploidy' describes the condition in which somatic cells of an individual contain three sets of chromosomes. In a few fish species, including goldfish (Carassius auratus Linnaeus, 1758), Prussian carp (Carassius gibelio Bloch, 1782), spined loach (Cobitis taeinia Linnaeus, 1758), natural diploid-polyploid complexes have been described (Zhou et al. 2000; Janko et al. 2007; Juchno and Boroń 2006; Xiao et al. 2011). In such cases, triploid females are fertile and can reproduce gynogenetically with non-reduced triploid eggs. In the Iberian minnow (Squalius alburnoides Steindachner, 1866) and pond loach (Misgurnus anguillicaudatus Cantor, 1842), allotriploid (containing three sets of chromosomes that are derived from different species) females produce haploid, diploid or triploid eggs (Zhang \& Arai 1999; Alves et al 2004; Morishima et al 2004). On the other hand, spontaneous autopolyploidy has been reported in several fish species, including California roach Hesperoleucus symmetricus Baird \& Girard, 1854 (Gold \& Avise 1976), rainbow trout (Thorgaard \& Gall 1979; Ocalewicz \& Dobosz 2009), nurse shark Ginglymostoma cirratum Bonnaterre, 1788 (Kendall et al. 1994) and pond loach (Zhang \& Arai 1999). Such a condition may occur as a result of impaired gametogenesis caused by cytogenetic changes during meiosis, including pre-meiotic endoduplication of a set of chromosomes, suppression of the first or second meiotic division (Cherfas et al 1995), and/or lack of disjunction of mitotic chromosomes during the first embryo cell cleavage. Suppression of the second meiotic division was observed in poor-quality post-ovulatory ageing oocytes (Aegerter \& Jalabert 2004; Flajšhans et al. 2007). Triploid individuals can be obtained by mating tetraploid and diploid individuals, as reported in pond loach (Arai \& Fujimoto 2013; Zhou et al. 2018), rainbow trout (Chourrout et al. 1986;
Blanc et al. 1987; Myers \& Hershberger 1991; Quillet et al. 1988) and Iberian minnow (Alves et al. 2001), or by dispermic fertilization of an haploid egg (Ueda et al. 1986; Grunina et al. 2006). Moreover, exposure of activated eggs to chemical (colchicine, ether, deuterium oxide and specific enzyme inhibitors) or physical (sub-lethal temperature or high hydrostatic pressure HHP) shock shortly after fertilization also results in the development of triploid specimens (Piferrer et al. 2009). In fish, ovulated eggs are arrested at the metaphase of the second meiotic division and sperm-induced activation of eggs is followed by re-initiation of meiosis and extrusion of the second polar body (Arai \& Fujimoto 2013). Chemical, HHP and temperature shock applied to activated/fertilized eggs disrupts microtubules of the meiotic spindle, which prevents extrusion of the second polar body and results in the development of triploid embryos (Thorgaard 1986; Pandian \& Koteeswaran 1998). Embryos produced by this method consist of a haploid set of chromosomes from the egg nucleus, a haploid set of chromosomes from the sperm nucleus and an additional haploid set of chromosomes from the second polar body nucleus (Arai \& Fujimoto 2013). The additional set of chromosomes in triploid fish causes cytogenetic incompatibility that impairs normal gonadal development and gamete production (Benfey 1999). Some of the triploid females show highly reduced ovaries, which are usually unable to produce eggs. Whereas triploid males develop testes to the size observed in diploid individuals, however, such fish are usually infertile due to the aneuploidy of spermatozoa (Benfey 1999; Zhang \& Arai 1999; Piferrer et al. 2009; Zhou \& Gui 2017). Triploid fish are not affected by a decline in growth, survival and meat quality, which accompanies the process of sexual maturation in normal diploid specimens. Artificial triploidization is therefore a promising method for breeding fish species showing early sexual maturation (Arai 2001). As reported by Arai (2001), Hulata (2001) and Rothbard (2006), triploidization on a commercial scale has been applied to rainbow trout, Atlantic salmon (Salmo salar Linnaeus, 1758), masu salmon (Oncorhynchus masou Brevoort, 1856), ayu (Plecoglossus altivelis Temminck \& Schlegel, 1846), bastard halibut (Paralichthys olivaceus Temminck \& Schlegel, 1846), pond loach, black carp (Mylopharyngodon piceus Richardson, 1846) and grass carp (Ctenopharyngodon idella Valenciennes, 1844).

An important feature of triploid fish is that they are not considered to be genetically modified organisms (GMOs) and do not require extensive testing before being introduced to the market. Moreover, the sterility of triploid individuals inhibits interactions between fish that escaped from a fish farm and wild stocks. 
Unfortunately, it has been observed that produced triploids may show reduced survivability (Dunham 2004) and an increased incidence of skeletal deformities compared to their diploid siblings (Paschos et al. 2001; Sadler et al. 2001: Opstad et al. 2013). In the triploid Atlantic cod (Gadus morhua Linnaeus, 1758), the most common deformities were lordosis and cervical deformations (Opstad et al. 2013). The triploid Argentinian silverside (Odontesthes bonariensis Valenciennes, 1835) exhibited ocular deformities, dilation of the pericardial cavity, bulges in the head, and either curling or bending of the body (Strüssmann et al. 1993), while a short curved tail and an edematous body were described in the triploid Mozambique tilapia Oreochromis mossambicus Peters, 1852 (Varadaraj \& Pandian 1990). Jaw and body deformities (scoliosis, lordosis and humpback deformities), a short opercula and non-cranial deformities were described in triploid Atlantic salmon (O'Flynn et al. 1997; Sadler et al. 2001; Fjelldal \& Hansen 2010), whereas triploid brook trout (Salvelinus fontinalis Mitchill, 1814) exhibited scoliosis, lordosis, presence of spiral larvae and double-headed larvae (Galbreath \& Samples 2000). Deformed individuals show problems with swimming and difficulties in food intake (Boglione et al. 2013).

The objective of this study was to compare the ratio and variety of body deformities in rainbow trout from diploid and triploid commercially produced stocks. External body shape examination, radiography and whole-mount skeletal staining were performed to determine body deformities in the studied rainbow trout. All these methods were used to obtain complementary and detailed information on spinal deformities in diploid and triploid rainbow trout.

\section{Materials and methods}

The study was conducted in compliance with the recommendations stipulated in the Polish ACT of 21 January 2005 on Animal Experiments (Dz. U. of 2005, No. 33, item 289).

The examined rainbow trout from the Rutki strain (14-month-old specimens) originated from diploid $\left(n_{2 n}=886\right)$ and triploid $\left(n_{3 n}=732\right)$ stocks produced and kept at the Department of Salmonid Research, Inland Fisheries Institute (IFI) in Olsztyn, Rutki, Poland. The diploid chromosome number in rainbow trout specimens from the strain used in this experiment is varied (58-62), while the chromosome arm number (Fundamental Number, FN) remains stable at 104 (Robertsonian polymorphism; Ocalewicz 2002).

A triploid stock of rainbow trout was produced using a routine procedure that involves a $3 \mathrm{~min}$ high hydrostatic pressure (HHP) shock (9500 psi) applied 35 min after egg insemination using a TRC-APV electric/ hydraulic device (TRC Hydraulics Inc. Dieppe, Canada). From insemination to the application of the HHP shock, eggs were incubated in water at $10^{\circ} \mathrm{C}$. After hatching, diploid and triploid fish were kept under the same conditions in water from the Radunia stream. Water temperature ranged from 0 to $4^{\circ} \mathrm{C}$ in winter, from 4 to $16^{\circ} \mathrm{C}$ in spring, from 15 to $22^{\circ} \mathrm{C}$ in summer and from 5 to $14^{\circ} \mathrm{C}$ in autumn. Oxygen concentration ranged from 80 to $90 \%$ and $\mathrm{pH}$ was about 7 . The fish were fed with feed produced by Aller-Aqua, Christiansfeld, Denmark (larvae - Aller Infa Ex 0.4 mm, Aller Futura Ex 0.5-1.0 mm, Aller Performa 1.3 mm, 1.5 $\mathrm{mm}$ and $2 \mathrm{~mm}$, after reaching $50 \mathrm{~g}$ - feed Aller Silver 3 $\mathrm{mm})$. Feed portions were related to water temperature, calorific value, average fish sizes and corresponded to the manufacturer's recommendations. The fish were fed 5-8 times per day depending on the season with a natural photoperiod. Eggs and larvae were kept until yolk sac resorption in a $30 \times 30 \times 10 \mathrm{~cm}$ nursery with a water flow rate of $5 \mathrm{I} \mathrm{min}^{-1}$. After the yolk sac resorption, fish were transported to $2 \times 2 \times 0.3 \mathrm{~m}$ plastic pools with $1.2 \mathrm{~m}^{3}$ water and a water flow rate of $30-50 \mathrm{I} \mathrm{min}^{-1}$. From $20 \mathrm{~g}$ of body weight, fish were kept in $3 \times 3 \times 0.4 \mathrm{~m}$ concrete pools with a water flow rate of $50-1001 \mathrm{~min}^{-1}$.

\subsection{Analysis of deformations}

A total of 732 and 886 individuals from triploid and diploid stocks, respectively, were screened for visible skeletal deformities. In addition, 115 diploids and 103 triploids were randomly selected, measured and weighed.

All individuals exhibiting skeletal deformities and four individuals without any abnormalities were sedated and transported to a veterinary clinic (Klinika dla zwierząt $24 \mathrm{H}$, Gdynia, Poland) for X-ray imaging (Gierth HS80, 50 kWh, 0.4 s, $101 \mathrm{~cm}$ ). After X-rays were taken, the same fish were subjected to a whole-mount skeletal staining procedure (Dingerkus \& Uhler 1977). The fish were fixed in formaldehyde (10\%) for 3 days and then washed in distilled water for another 3 days. The eviscerated and skinned fish were placed for $48 \mathrm{~h}$ in $100 \mathrm{ml}$ of alcian blue solution (solution $\mathrm{A} ; 10 \mathrm{mg}$ of alcian blue, $80 \mathrm{ml}$ of $95 \%$ ethanol and $20 \mathrm{ml}$ of glacial acetic acid). After this step, the fish were washed twice in $95 \%$ ethanol and in the series of ethanol for $3 \mathrm{~h}$ each $(75 \%, 45 \%$ and $15 \%)$ and transferred to the digestive mixture $(30 \mathrm{ml}$ of saturated aqueous sodium borate, $70 \mathrm{ml}$ of distilled water, $1 \mathrm{~g}$ of pancreatic trypsin; Pancreatin $4 \times$ USP, Sigma) for 12 to 25 days (depending on fish size) until bones and cartilage 
were clearly visible (from 12 to 25 days depending on fish size). During incubation, the solution was replaced every 2 to 4 days with a freshly prepared solution. The fish were then placed in solution B (aqueous 0.5\% $\mathrm{KOH}$ and $0.5 \%$ alizarin S) for $24 \mathrm{~h}$. The fish were then passed through a graded series of $0.5 \% \mathrm{KOH} /$ glycerin bleaching solutions (3:1, 1:1, 1:3) for $24 \mathrm{~h}$ each. Between 3 to 4 drops of $3 \% \mathrm{H}_{2} \mathrm{O}_{2}$ were added per $100 \mathrm{ml}$ of 3:1 and 1:1 KOH-glycerin solution to bleach pigments of dark specimens. Finally, individuals were transferred to pure glycerol (Dingerkus \& Uhler 1977).

\subsection{Cytogenetic analysis}

Cytogenetic studies were carried out on randomly selected four specimens from the triploid stock and two individuals from the diploid control groups. Somatic metaphase chromosomes were prepared from cephalic kidney cells according to the method described by Ocalewicz et al. (2013).

\subsection{Statistical analysis}

The weight and length of the examined rainbow trout were compared using Student's t-test. All calculations were performed using Statistica version 12 (StatSoft). Differences between the results were assessed as significant at $p<0.05$. All values in the text are expressed as means \pm standard deviations (S.D.).

\section{Results}

The triploid state was confirmed in the rainbow trout from the stock produced as a result of the HHP shock applied to fertilized eggs to prevent the release of the 2 nd polar body (Fig. 1). The average length $(\mathrm{cm})$ of diploids and triploids was $14.6 \pm 1.8$ and $15.2 \pm 1.8$, respectively, and their average weight (g) was $33.2 \pm 11.5$ and $39.7 \pm 13.1$, respectively. Statistical analysis (Student's t-test) showed significant differences in body weight between the groups of diploid and triploid juvenile rainbow trout $(p<0.05)$. The differences in body length were not statistically significant $(p<0.05)$.

Individuals with body deformities were found among diploids $(n=4)$ and triploids $(n=28)$, representing up to $0.45 \%$ and $3.83 \%$ of the examined fish from each stock, respectively. Among the deformed diploids, two individuals had a malformed jaw $(0.23 \%)$, one fish had a shortened tail $(0.11 \%)$ and one trout had scoliosis $(0.11 \%)$. The most frequently observed deformity among triploids was humpback (2.05\%), and eight fish had a shortened tail (1.23\%). One individual showed both of these deformities.

The spine of the analyzed rainbow trout consists of 55-64 vertebrae (Fig. 2A). The whole-mount skeletal staining and radiography of a diploid individual with a deformed tail showed deformed vertebrae in the hemal area (40-47): vertebrae from 40 to 42 were compressed and vertebrae from 43 to 47 were fused
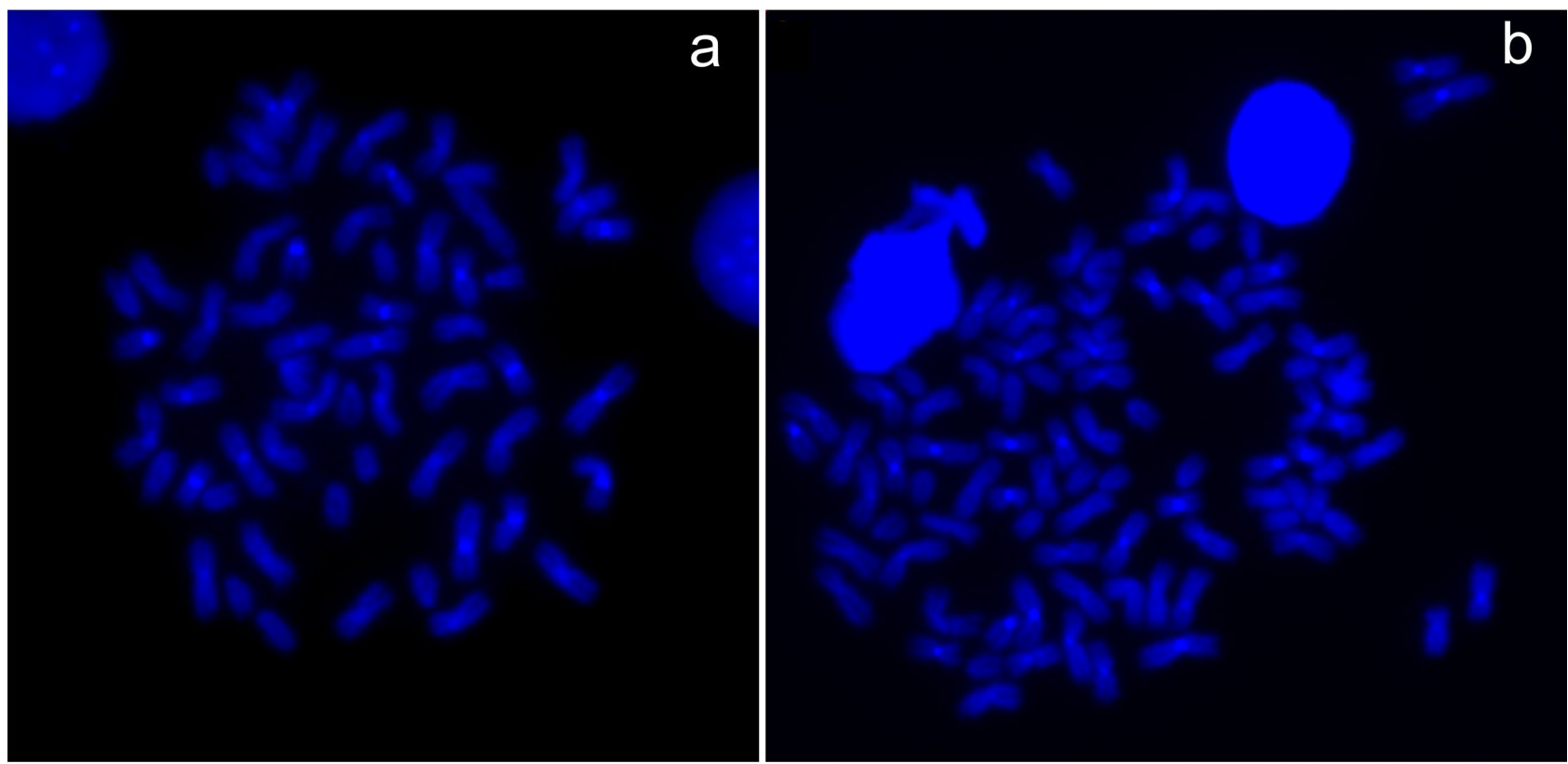

\section{Figure 1}

Metaphase spreads with 58 (a) and 91 (b) chromosomes prepared from the diploid and triploid rainbow trout (Oncorhynchus mykiss) 

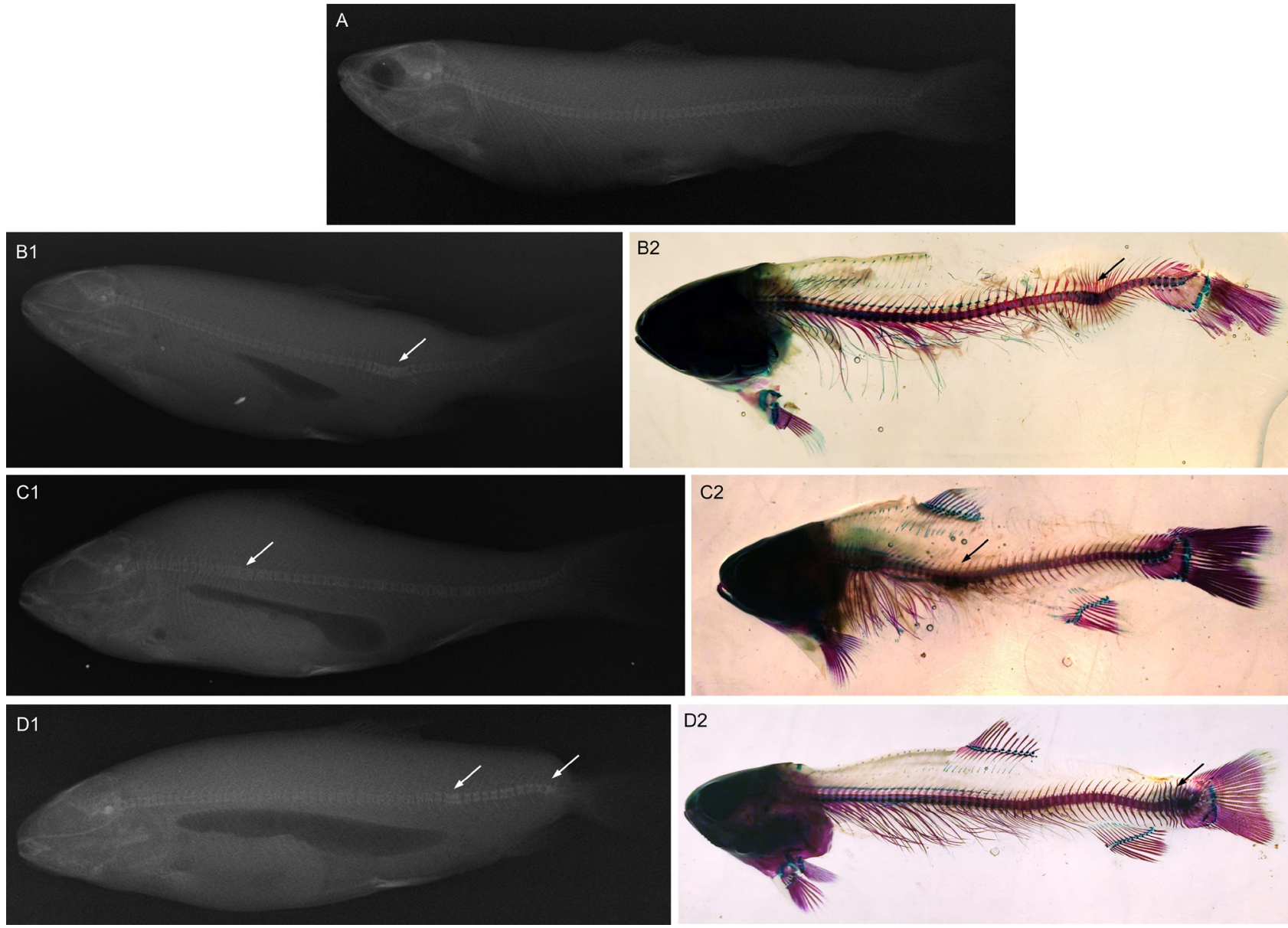

\section{Figure 2}

Skeletal deformities of fish visualized by radiography (1) and whole-mount skeletal staining (2); A - radiography of fish with properly developed vertebrae, B - fish with compressed and fused vertebrae in the hemal area (arrows), C - fish with compressed vertebrae in the pre-hemal area (arrows), D - fish with a deformed tail, compressed and fused vertebrae in the hemal and caudal area (arrows)

(Fig. 2B). The diploid individual with scoliosis exhibited fusion of the first five vertebrae.

Vertebral deformities were more frequently observed in the analyzed triploid individuals. Deformities involving fusions or compression of vertebrae were observed in almost all (excluding individuals with a sole jaw deformity) individuals with externally visible deformities (3.14\%). The most common abnormality (2.05\%) in the triploid fish was the compression of vertebrae, mostly from the pre-hemal area (8-14 vertebrae), which was externally observed as a hump (Fig. 2C). Less common was the compression and fusion of vertebrae in the hemal and caudal area from the 30-38th vertebrae up to the last vertebrae, resulting in a shortened tail (1.23\%; Fig. 2D).

\section{Discussion}

Nowadays, the use of sterile triploid specimens is becoming increasingly common in the aquaculture sector and in the fisheries management (Zhou \& Gui 2017). An advantage of rearing sterile fish is the reduction of losses related to negative consequences of premature sexual maturation, including a reduced growth rate, altered meat quality, increased aggressive behavior and mortality (Taranger et al. 2010). All-female production of sterile trout allows rearing of fish to the weight at which conventional production is ineffective due to sexual maturation. Several studies show that the induction of triploidy in rainbow 
trout has a positive effect on the body and fillet development, however, the muscle of triploids may sometimes exhibit slightly inferior flesh characteristics, including slightly reduced firmness (Poontawee et al. 2007; Aussanasuwannakul et al. 2011; Lefevre al. 2015). The sterility of fish also protects the flesh from the catabolism of proteins and fat content loss, which may occur during maturation (Aussanasuwannakul et al. 2011).

Due to the lack of sexual maturation and large size of cells, triploid fish are expected to reach a higher body weight than their diploid siblings. Differences in the growth rate between triploid and diploid fish depend on the species, developmental stage and environmental conditions (Piferrer et al. 2009). After 14 months of rearing under aquaculture conditions, the weight of the triploid rainbow trout examined in this study significantly exceeded the weight of the diploids. Although some other studies on triploid salmonid species show similar trends (O'Flynn et al. 1997; Oppedal et al. 2003), there are reports showing no significant differences between the weight of juvenile triploid and diploid fish (Cotter et al. 2002; Aussanasuwannakul et al. 2011). On the other hand, during the early development stages, triploids tend to have a lower body weight compared to diploids, a trend that persists until the maturation stage (Solar et al. 1984; Chourrout et al. 1986; Withler et al. 1995; Chiasson et al. 2009). A similar pattern was observed in the Atlantic salmon, where diploid females of Salmo salar showed significantly greater weight than triploids 17 months after the post-feeding stage (Galbreath et al. 1994).

Literature and experimental data show that triploids tend to exhibit a higher incidence of body deformities than diploids (Piferrer et al. 2009; Taranger et al. 2010). In this study, the ratio of deformed specimens in the diploid group was low $(0.45 \%)$ and the deformities themselves were minor. In the triploid rainbow trout group, the ratio of fish with body deformities increased to $3.83 \%$, but was still lower than in other reports, where up to $48 \%$ of triploid individuals have some body deformities (Madsen et al. 2000; Weber et al. 2014). In other salmonids, deformities were also observed among triploids. A fairly low rate of deformed individuals (c. 1.8\%) was observed in the brown trout Salmo trutta m. fario (Preston et al. 2013). In the Atlantic salmon, deformity rates ranged from 2 to $48.9 \%$ in triploids and from 0.66 to $24.4 \%$ in their diploid counterparts (O'Flynn et al. 1997; Sadler et al. 2001; Cotter et al. 2002; Fjelldal \& Hansen 2010: Leclercq et al. 2011; Fraser et al. 2013; Taylor et al. 2014). Studies on triploidization of the Atlantic cod showed that $72 \%$ of triploids and $42 \%$ of their diploid siblings had body abnormalities (Opstad et al., 2013). The Argentinian silverside showed a $13.89-33.33 \%$ incidence of deformities among triploids and $0-3.19 \%$ among the diploid fish (Strüssmann et al. 1993). The Mozambique tilapia showed $7-23 \%$ deformities in triploids and $2-6 \%$ in diploids (Varadaraj \& Pandian, 1990).

An increased ratio of deformed fish among triploids may occur during exposure of fertilized eggs to the HHP shock used for triploidization (Huergo \& Zaniboni-Filho 2006). It has been proven that HHP may delay the epiboly and suppress the dorso-ventral differentiation in fish (Yamaha et al. 2002). Triploid fish obtained through crossbreeding of tetraploid and diploid fish show a lower deformation rate than triploids produced by applying temperature or pressure shock, which confirms that manipulations on activated eggs should be considered responsible for deformations of triploids (Myers \& Hershberger 1991; Weber et al. 2014). On the other hand, triploidy in itself may disturb the process of body development. A number of published studies show that higher supplementation of phosphorous and proteins in feed correlates with lower deformity rates among triploids (Fjelldal et al. 2016; Smedley et al. 2016). However, other results demonstrate no significant differences in deformity rates between juvenile diploids and triploids during feeding with feed optimal for diploids (Burke et al. 2010; Peruzzi et al. 2018).

The majority of deformities observed after radiography and whole-mount skeletal staining were spinal deformities, including compression and fusion of vertebrae (Fig. 2.B,C,D). Radiography enabled better examination of the cephalic vertebrae, whereas the whole-mount skeletal staining allowed more accurate observation of other vertebrae. Deformities in the thoracic region led to the observation of fish with humpback, while deformities in the caudal area resulted in the phenotype with a shortened tail (Fig. 2D). Similar deformities were previously described in the triploid rainbow trout (Weber et al. 2014) and in the triploid Atlantic salmon (Cotter et al. 2002; Fjelldal \& Hansen 2010). The presence of body deformities in aquaculture species is one of the most important problems in fish farming. The deformities observed in the diploid and triploid rainbow trout examined in this study were non-lethal, however, they can negatively affect the condition of fish, disturb the growth rate and cause swimming and food intake difficulties. As fish with body abnormalities are not aesthetically pleasing to the customers, increased ratios of skeletal deformities among fish produced for the commercial purpose may result in real economic losses (Hough 2009). Moreover, any deviation from the standards 
of the spinal morphology spotted at the slaughter line can lead to problems with proper fish processing (Helland et al. 2005).

\section{Conclusion}

The presented study indicates that triploid rainbow trout individuals obtained through the HHP shock exhibited more body deformities than diploids. Compared to studies on other triploid species, the deformity rate in the triploid rainbow trout examined in this study was relatively low (3.83\%). The most common deformities observed in triploid individuals were vertebral compression in the pre-hemal region, resulting in the humpback phenotype, and vertebral compression in the hemal and caudal regions, resulting in shortened tails in these individuals. Although the triploid rainbow trout from the examined stock showed an increased ratio of deformed specimens, differences between triploid and diploid individuals under these conditions were small, which, given the profits related to sterility of triploid fish, makes this method efficient in the aquaculture of rainbow trout from the farm under study.

\section{Acknowledgements}

We thank Stefan Dobosz and Rafał Rożyński from the Department of Salmonid Research, Inland Fisheries Institute in Olsztyn, Rutki, for their technical assistance during the experiment.

\section{References}

Aegerter, S. \& Jalabert, B. (2004). Effects of post-ovulatory oocyte ageing and temperature on egg quality and on the occurrence of triploid fry in rainbow trout, Oncorhynchus mykiss. Aquaculture 231(1-4): 59-71. DOI: 10.1016/j. aquaculture.2003.08.019.

Alves, M.J., Coelho, M.M. \& Collares-Pereira, M.J. (2001). Evolution in action through hybridisation and polyploidy in an Iberian freshwater fish: a genetic review. Genetica 111(1-3): 375-385. DOI: 10.1023/A:1013783029921.

Alves, M.J., Gromicho, M., Collares-Pereira, M.J., Crespo-López, E. \& Coelho, M.M. (2004). Simultaneous production of triploid and haploid eggs by triploid Squalius alburnoides (Teleostei: Cyprinidae). J. Exp. Zoolog. Part A Comp. Exp. Biol. 301(7): 552-558. DOI: 10.1002/jez.a.51.

Arai, K. (2001). Genetic improvement of aquaculture finfish species by chromosome manipulation techniques in Japan. Aquaculture 197(1-4): 205-228. DOI: 10.1016/
S0044-8486(01)00588-9.

Arai, K. \& Fujimoto, T. (2013). Genomic constitution and atypical reproduction in polyploid and unisexual lineages of the Misgurnus loach, a teleost fish. Cytogenet. Genome. Res. 140(2-4): 226-240. DOI: 10.1159/000353301.

Aussanasuwannakul, A., Kenney, P.B., Weber, G.M., Yao, J., Slider, S.D. et al. (2011). Effect of sexual maturation on growth, fillet composition, and texture of female rainbow trout (Oncorhynchus mykiss) on a high nutritional plane. Aquaculture 317(1-4): 79-88. DOI: 10.1016/j. aquaculture.2011.04.015.

Benfey, T.J. (1999). The physiology and behavior of triploid fishes. Rev. Fish. Sci. 7(1): 39-67. DOI: 10.1080/10641269991319162.

Blanc, J. M., Chourrout, D. \& Krieg, F. (1987). Evaluation of juvenile rainbow trout survival and growth in half-sib families from diploid and tetraploid sires. Aquaculture 65(3-4): 215-220. DOI: 10.1016/0044-8486(87)90233-X.

Boglione C., Gisbert E., Gavaia P., Witten P.E., Moren, M. et al. (2013). Skeletal anomalies in reared European fish larvae and juveniles. Part 2: main typologies, occurrences and causative factors. Rev. Aquacult. 5: 121-167. DOI: 10.1111/ raq.12016.

Burke, H.A., Sacobie, C.F., Lall, S.P. \& Benfey, T.J. (2010). The effect of triploidy on juvenile Atlantic salmon (Salmo salar) response to varying levels of dietary phosphorus. Aquaculture 306(1-4): 295-301. DOI: 10.1016/j. aquaculture.2010.05.002.

Cherfas, N., Gomelsky, B., Ben-Dom, N. \& Hulata, G. (1995). Evidence for the heritable nature of spontaneous diploidization in common carp, Cyprinus carpio L., eggs. Aquac. Res. 26(4): 289-292.

Chiasson, M.A., Pelletier, C.S. \& Benfey, T.J. (2009). Triploidy and full-sib family effects on survival and growth in juvenile Arctic charr (Salvelinus alpinus). Aquaculture 289(3-4), 244-252. DOI: 10.1016/j.aquaculture.2009.01.010.

Chourrout, D., Chevassus, B., Krieg, F., Happe, A., Burger, G. et al. (1986). Production of second generation triploid and tetraploid rainbow trout by mating tetraploid males and diploid females - potential of tetraploid fish. Theor. App. Genet. 72(2): 193-206. DOI: 10.1007/BF00266992.

Cotter, D., O'Donovan, V., Drumm, A., Roche, N., Ling, E.N. et al. (2002). Comparison of freshwater and marine performances of all-female diploid and triploid Atlantic salmon (Salmo salar L.). Aquac. Res. 33(1): 43-53. DOI: 10.1046/j.1355-557X.2001.00643.x.

Dingerkus, G. \& Uhler, L.D. (1977). Enzyme clearing of alcian blue stained whole small vertebrates for demonstration of cartilage. Stain Technol. 52(4): 229-232. DOI: 10.3109/10520297709116780.

Dunham, R.A. (2004). Aquaculture and fisheries biotechnology: genetic approaches. Oxfordshire, UK: CABI Publishing.

Fjelldal, P.G. \& Hansen, T. (2010) Vertebral deformities in triploid Atlantic salmon (Salmo salar L.) underyearling 
smolts. Aquaculture 309: 131-136. DOI: 10.1016/j. aquaculture.2010.09.027.

Fjelldal, P.A., Hansen, T.J., Lock, E.J., Wargelius, A., Fraser, T.W.K. et al. (2016). Increased dietary phosphorous prevents vertebral deformities in triploid Atlantic salmon (Salmo salar L.). Aquacul. Nutr. 22(1): 72-90. DOI: 10.1111/ anu.12238.

Flajšhans, M., Kohlmann, K. \& Rab, P. (2007). Autotriploid tench Tinca tinca (L.) larvae obtained by fertilization of eggs previously subjected to postovulatory ageing in vitro and in vivo. J. Fish Biol. 71(3): 868-876. DOI: 10.1111/j.10958649.2007.01557.x.

Fraser, T.W., Hansen, T., Skjæraasen, J.E., Mayer, I., Sambraus, F. et al. (2013). The effect of triploidy on the culture performance, deformity prevalence, and heart morphology in Atlantic salmon. Aquaculture 416: 255-264. DOI: 10.1016/j.aquaculture.2013.09.034.

Galbreath, P.F. \& Samples B.L. (2000). Optimization of thermal shock protocols for induction of triploidy in brook trout. N. Am. J. Aquacult. 62: 249-259. DOI: 10.1577/1548-8454(2000)062<0249:OOTSPF>2.0.CO;2.

Galbreath, P.F., Jean, W.S., Anderson, V. \& Thorgaard, G.H. (1994). Freshwater performance of all-female diploid and triploid Atlantic salmon. Aquaculture 128(1-2): 41-49. DOI: 10.1016/0044-8486(94)90100-7.

Gold, J.R. \& Avise, J.C. (1976). Spontaneous triploidy in the California roach Hesperoleucus symmetricus (Pisces: Cyprinidae). Cytogenet. Genome Res. 17(3): 144-149. DOI: 10.1159/000130706.

Grunina, A.S., Recoubratsky, A.V., Tsvetkova, L.I. \& Barmintsev, V.A. (2006). Investigation on dispermic androgenesis in sturgeon fish. The first successful production of androgenetic sturgeons with cryopreserved sperm. Int. J. Refrig. 29(3): 379-386. DOI: 10.1016/j.ijrefrig.2005.07.009.

Helland, S., Refstie, S., Espmark, Å., Hjelde, K. \& Baeverfjord, G. (2005). Mineral balance and bone formation in fastgrowing Atlantic salmon parr (Salmo salar) in response to dissolved metabolic carbon dioxide and restricted dietary phosphorus supply. Aquaculture 250(1-2): 364-376. DOI: 10.1016/j.aquaculture.2005.03.032.

Huergo, G.M. \& Zaniboni-Filho, E. (2006). Triploidy induction in jundiá, Rhamdia quelen, through hydrostatic pressure shock. J. App. Aquaculture 18(4): 45-57. DOI: 10.1300/ J028v18n04_04.

Hough, C. (2009). Improving the sustainability of European fish aquaculture by the control of malformations. FINEFISH Final Workshop, Larvi 2009 - 5th Fish \& Shellfish Larviculture Symposium; 7-10 September 2009, Ghent University, Belgium.

Hulata, G. (2001). Genetic manipulations in aquaculture: a review of stock improvement by classical and modern technologies. Genetica 111(1-3): 155-173. DOI: 10.1023/A:1013776931796.

Janko, K., Bohlen, J., Lamatsch, D., Flajšhans, M., Epplen, J.T. et al. (2007). The gynogenetic reproduction of diploid and triploid hybrid spined loaches (Cobitis: Teleostei), and their ability to establish successful clonal lineages - on the evolution of polyploidy in asexual vertebrates. Genetica 131(2): 185-194. DOI: 10.1007/s10709-006-9130-5.

Juchno, D. \& Boroń, A. (2006). Age, reproduction and fecundity of the spined loach Cobitis taenia L. (Pisces, Cobitidae) from Lake Klawój (Poland). Reprod. Biol. 6(2): 133-148.

Kendall, C., Valentino, S., Bodine, A.B. \& Luer, C.A. (1994). Triploidy in a nurse Shark, Ginglymostoma cirratum. Copeia 1994(3): 825-827. DOI: 10.2307/1447205.

Leclercq, E., Taylor, J.F., Fison, D., Fjelldal, P.G., Diez-Padrisa, M. et al. (2011). Comparative seawater performance and deformity prevalence in out-of-season diploid and triploid Atlantic salmon (Salmo salar) post-smolts. Comp. Biochem. Phys. A 158(1): 116-125. DOI: 10.1016/j.cbpa.2010.09.018.

Lefevre, F., Cardinal, M., Bugeon, J., Labbe, L., Medale, F. et al. (2015). Selection for muscle fat content and triploidy affect flesh quality in pan-size rainbow trout, Oncorhynchus mykiss. Aquaculture 448: 569-577. DOI: 10.1016/j. aquaculture.2015.06.029.

Madsen, L., Arnbjerg, J. \& Dalsgaard, I. (2000). Spinal deformities in triploid all-female rainbow trout (Oncorhynchus mykiss). B. Eur. Assoc. Fish Pat. 20(5): 206-208.

Morishima, K., Oshima, K., Horie, S., Fujimoto, T., Yamaha, E. et al. (2004). Clonal diploid sperm of the diploid-triploid mosaic loach, Misgurnus anguillicaudatus (Teleostei: Cobitidae). J. Exp. Zoolog. Part A Comp. Exp. Biol. 301(6): 502-511. DOI: 10.1002/jez.a.49.

Myers, J.M. \& Hershberger, W.K. (1991). Early growth and survival of heat-shocked and tetraploid-derived triploid rainbow trout (Oncorhynchus mykiss). Aquaculture 96(2): 97-107. DOI: 10.1016/0044-8486(91)90142-T.

Ocalewicz, K. (2002). Cytogenetic markers for X chromosome in karyotype of rainbow trout from Rutki strain. Folia Biol. (Krakow) 50: 10-14.

Ocalewicz, K. \& Dobosz, S. (2009). Karyotype variation in the albino rainbow trout (Oncorhynchus mykiss (Walbaum)). Genome 52(4): 347-352. DOI: 10.1139/G09-009.

Ocalewicz, K., Kuzminski, H., Pomianowski, K. \& Dobosz, S. (2013). Induction of androgenetic development of the brook charr (Salvelinus fontinalis) $\times$ Arctic charr (Salvelinus alpinus) hybrids in eggs derived from the parental species. Reprod. Biol. 13: 105-112. DOI: 10.1016/j. repbio.2013.03.002.

O'Flynn, F.M., McGeachy, S.A., Friars, G.W., Benfey, T.J. \& Bailey, J.K. (1997). Comparisons of cultured triploid and diploid Atlantic salmon (Salmo salar L.). ICES J. Mar. Sci. 54: 11601165. DOI: 10.1016/S1054-3139(97)80022-7.

Oppedal, F., Taranger, G.L. \& Hansen, T. (2003). Growth performance and sexual maturation in diploid and triploid Atlantic salmon (Salmo salar L.) in seawater tanks exposed to continuous light or simulated natural photoperiod. Aquaculture 215(1-4), 145-162. DOI: 10.1016/S0044- 
8486(02)00223-5.

Opstad, I., Fjelldal, P.G., Karlsen, Ø., Thorsen, A., Hansen, T.J. et al. (2013). The effect of triploidization of Atlantic cod (Gadus morhua L.) on survival, growth and deformities during early life stages. Aquaculture 388: 54-59. DOI: 10.1016/j.aquaculture.2013.01.015.

Pandian, T.A. \& Koteeswaran, R. (1998). Ploidy induction and sex control in fish. Hydrobiologia 384(1-3): 167-243. DOI: 10.1023/A:1003332526659.

Paschos, I., Natsis, L., Nathanailides, C., Kagalou, I. \& Kolettas, E. (2001). Induction of gynogenesis and androgenesis in goldfish Carassius auratus (var. oranda). Reprod. Domest. Anim. 36(3-4), 195-198. DOI: 10.1046/j.14390531.2001.00285.x.

Peruzzi, S., Puvanendran, V., Riesen, G., Seim, R.R., Hagen, Ø. et al. (2018). Growth and development of skeletal anomalies in diploid and triploid Atlantic salmon (Salmo salar) fed phosphorus-rich diets with fish meal and hydrolyzed fish protein. PLoS One 13(3): e0194340. DOI: 10.1371/journal. pone.0194340.

Piferrer, F., Beaumont, A., Falguière, J.C., Flajšhans, M., Haffray, P. et al. (2009). Polyploid fish and shellfish: production, biology and applications to aquaculture for performance improvement and genetic containment. Aquaculture 293(3-4): 125-156. DOI: 10.1016/j. aquaculture.2009.04.036.

Poontawee, K., Werner, C., Müller-Belecke, A., HörstgenSchwark, G. \& Wicke, M. (2007). Flesh qualities and muscle fiber characteristics in triploid and diploid rainbow trout. J. Appl. Ichthyol. 23(3): 273-275. DOI: 10.1111/j.14390426.2007.00843.x.

Preston, A.C., Taylor, J.F., Craig, B., Bozzolla, P., Penman, D.J. et al. (2013). Optimisation of triploidy induction in brown trout (Salmo trutta L.). Aquaculture 414: 160-166. DOI: 10.1016/j. aquaculture.2013.07.034.

Quillet, E., Chevassus, B. \& Devaux, A. (1988). Timing and duration of hatching in gynogenetic, triploid, tetraploid, and hybrid progenies in rainbow trout. Genet. Sel. Evol. 20 (2), 199-210. DOI: 10.1186/1297-9686-20-2-199.

Rothbard, S. (2006). A review of ploidy manipulations in aquaculture: the Israeli experience. Isr. J. Aquac.-Bamidgeh 58: 266-279.

Sadler, J., Pankhurst, P.M. \& King, H.R. (2001). High prevalence of skeletal deformity and reduced gill surface area in triploid Atlantic salmon (Salmo salar L.). Aquaculture 198(3-4): 369-386. DOI: 10.1016/S0044-8486(01)00508-7.

Smedley, M.A., Clokie, B.G., Migaud, H., Campbell, P., Walton, J. et al. (2016). Dietary phosphorous and protein supplementation enhances seawater growth and reduces severity of vertebral malformation in triploid Atlantic salmon (Salmo salar L.). Aquaculture 451: 357-368. DOI: 10.1016/j.aquaculture.2015.10.001.

Solar, I.I., Donaldson, E.M. \& Hunter, G.A. (1984). Induction of triploidy in rainbow trout (Salmo gairdneri Richardson) by heat shock, and investigation of early growth. Aquaculture 42(1): 57-67. DOI: 10.1016/0044-8486(84)90313-2.

Strüssmann, C.A., Choon, N.B., Takashima, F. \& Oshiro, T. (1993). Triploidy induction in an atherinid fish, the pejerrey (Odontesthes bonariensis). Prog. Fish-Cult. 55(2): 83-89. DOI: 10.1577/1548-8640(1993)055<0083:TIIAAF>2.3.CO;2.

Taranger, G.L., Carrillo, M., Schulz, R.W., Fontaine, P., Zanuy, S. et al. (2010). Control of puberty in farmed fish. Gen. Comp. Endocrinol. 65(3): 483-515. DOI: 10.1016/j. ygcen.2009.05.004.

Taylor, J.F., Bozzolla, P., Frenzl, B., Matthew, C., Hunter, D. et al. (2014). Triploid Atlantic salmon growth is negatively affected by communal ploidy rearing during seawater grow-out in tanks. Aquaculture 432: 163-174. DOI: 10.1016/j.aquaculture.2014.05.014.

Thorgaard, G.H. \& Gall, G.A. (1979). Adult triploids in a rainbow trout family. Genetics 93(4): 961-973.

Thorgaard, G.H. (1986). Ploidy manipulation and performance. Aquaculture 57(1-4): 57-64. DOI: 10.1016/00448486(86)90180-8.

Ueda, T., Kobayashi, M. \& Sato, R. (1986). Triploid rainbow trouts induced by polyethylene glycol. Proc. Japan Acad. Ser. B 62(5): 161-164. DOI: 10.2183/pjab.62.161.

Varadaraj, K. \& Pandian, T.J. (1990). Production of all-female sterile-triploid Oreochromis mossambicus. Aquaculture 84: 117-123. DOI: 10.1016/0044-8486(90)90342-K.

Weber, G.M., Hostuttler, M.A., Cleveland, B.M. \& Leeds, T.D. (2014). Growth performance comparison of intercross-triploid, induced triploid, and diploid rainbow trout. Aquaculture 433: 85-93. DOI: 10.1016/j. aquaculture.2014.06.003.

Withler, R.E., Beacham, T.D., Solar, I.I. \& Donaldson, E.M. (1995). Freshwater growth, smolting, and marine survival and growth of diploid and triploid coho salmon (Oncorhynchus kisutch). Aquaculture 136(1-2): 91-107. DOI: 10.1016/00448486(95)01036-X.

Xiao, J., Zou, T., Chen, Y., Chen, L., Liu, S. et al. (2011). Coexistence of diploid, triploid and tetraploid crucian carp (Carassius auratus) in natural waters. BMC genet. 12(1): 20. DOI: 10.1186/1471-2156-12-20.

Yamaha, E., Otani, S., Minami, A. \& Arai, K. (2002). Dorsoventral axis perturbation in goldfish embryos caused by heat and pressure-shock treatments for chromosome set manipulation. Fish.Sci.68(2):313-319. DOI: 10.1046/j.14442906.2002.00427.x.

Zhang, Q. \& Arai, K. (1999). Aberrant meioses and viable aneuploid progeny of induced triploid loach (Misgurnus anguillicaudatus) when crossed to natural tetraploids. Aquaculture 175(1-2): 63-76. DOI: 10.1016/S00448486(99)00035-6.

Zhou, H., Xu, Q.Z., Zhang, R., Zhuang, Z.X., Ma, Y.Q. et al. (2018). Gonadal transcriptome analysis of hybrid triploid loaches (Misgurnus anguillicaudatus) and their diploid and tetraploid parents. PLoS One 13(5): e0198179. DOI: 
10.1371/journal.pone.0198179.

Zhou, L. \& Gui, J. (2017). Natural and artificial polyploids in aquaculture. Aquac. Fish. 2(3): 103-111. DOI: 10.1016/j. aaf.2017.04.003.

Zhou, L., Wang, Y. \& Gui, J.F. (2000). Genetic evidence for gonochoristic reproduction in gynogenetic silver crucian carp (Carassius auratus gibelio Bloch) as revealed by RAPD assays. J. Mol. Evol. 51(5): 498-506. DOI: 10.1007/ s002390010113. 